\title{
Binding of Low-Molecular-Weight Cationic Ligands to Chondroitin Sulfate as Studied by Capillary Electrophoresis Frontal Analysis
}

\author{
Jesper Østergaard", Henrik Jensen, Susan W. Larsen and Claus Larsen
}

\author{
Department of Pharmaceutics and Analytical Chemistry, Faculty of Pharmaceutical Sciences, University of \\ Copenhagen, Universitetsparken 2, DK-2100 Copenhagen, Denmark
}

\begin{abstract}
The feasibility of capillary electrophoresis frontal analysis for the study of low-molecular-weight ligandchondroitin sulfate interactions was investigated. The interaction of the 7 cationic ligands (lidocaine, propranolol, scopolamine, N-methyl scopolamine, N-butyl scopolamine, 2-propylisochinolinium, and methyl viologen) with the glycosaminoglycan chondroitin sulfate was investigated in $0.067 \mathrm{M}$ phosphate buffer, $\mathrm{pH} 7.4$, at $25^{\circ} \mathrm{C}$. A frontal analysis method with a short analysis time, suitable for ranking ligands according to degree of complexation for chondroitin sulfate was developed. The double charged ligand methyl viologen possessed the highest affinity for chondroitin sulfate. Linear binding isotherms were obtained and apparent association constants were determined. Capillary electrophoresis frontal analysis may be an attractive tool for characterization of ligand-glycosaminoglycan interactions.
\end{abstract}

Keywords: Affinity capillary electrophoresis, chondroitin sulfate, complexation, frontal analysis, drug-glycosaminoglycan interactions.

\section{INTRODUCTION}

Glycosaminoglycans, such as chondroitin sulfate, play an important role in biomedical sciences and pharmaceutics. These high-molecular-weight structures are present in most tissues and body fluids. Small-molecule amphiphilic drug substances may interact with glycosaminoglycans. It is known that drug substance-polyelectrolyte interactions can affect drug performance through the alteration of transport and distribution processes [1-3]. Furthermore investigations aimed at utilizing glycosaminoglycans in drug delivery systems are carried out [4-7]. For polymer-based drug delivery vehicles thorough knowledge of drug-polyelectrolyte interactions is advantageous. Ionic or electrostatic interactions may constitute a key factor influencing the degree of drug incorporation $[8,9]$ and release rates from such delivery systems $[4,5,10]$.

A range of methods have been applied to the study of low-molecular-weight ligand-polyelectrolyte complexation including equilibrium dialysis [11-13], isothermal titration calorimetry [14-16], ion selective electrodes [17, 18], and capillary electrophoresis (CE) [19-22]. CE has been established as an efficient micromethod for studying molecular interactions [23-28]. Different formats for conducting affinity $\mathrm{CE}$ have been developed; their pros and cons have been discussed previously [23, 26, 29-33]. The recognized advantages associated with the capillary electrophoresis frontal analysis (CE-FA) format (and affinity $\mathrm{CE}$ generally) are relatively short analysis times, simple method development, low sample consumption, and ease of automation. CE-FA has primarily been applied in studies of drug-albumin binding, e.g. [29, 34-43]. Also drug binding to

*Address correspondence to this author at the Department of Pharmaceutics and Analytical Chemistry, Faculty of Pharmaceutical Sciences, University of Copenhagen, Universitetsparken 2, DK-2100 Copenhagen, Denmark; Tel: +45 35336138; Fax: +45 35336030; E-mail: joe@farma.ku.dk $\alpha_{1}$-acid glycoprotein $[35,36]$, lipoproteins [44-46], liposomes [47, 48], and the polyelectrolyte dextran sulfate $[19,20]$ has been investigated by CE-FA.

Chondroitin sulfate is the most abundant glycosaminoglycan in cartilage and is widely distributed into body tissues and fluids [49]. It is a polysaccharide consisting of alternating $\mathrm{N}$-acetyl galactosamine and glucuronic acids, respectively, with the $\mathrm{N}$-acetyl galactosamine sulfated at the 4th or 6th position (Fig. 1). Chondroitin sulfate is known to interact with positively charged molecules $[16,50,51]$. In the search for novel intra-articular depot formulation principles for potential use in postoperative pain management and osteoarthritis [52], we are interested in chemical structures which can provide binding to the articular cartilage as a means for drug targeting and/or achievement of local sustained drug release. To this end, CEFA was evaluated as a rapid approach for identifying and ranking low-molecular-weight ligands possessing affinity to the articular cartilage constituent chondroitin sulfate. Here we report on the development of a CE-FA method feasible for characterization of low-molecular-weight ligand-chondroitin sulfate binding. For the cationic model compounds lidocaine, propranolol, scopolamine, N-methyl scopolamine, N-butyl scopolamine, 2-propylisochinolinium, and methyl viologen (Fig. 1) binding isotherms were constructed and apparent association constants determined. It is noted that the model compounds were selected based on their availability in the lab and structural properties. The possible effect of glycosaminoglycan interactions on pharmacokinetic and pharmacological effects upon administration of these compounds was not considered.

\section{MATERIALS AND METHODOLOGY}

\section{Chemicals}

Chondroitin sulfate (sodium salt) from bovine cartilage, lidocaine hydrochloride monohydrate, N-butyl scopolamine 
<smiles>CCN(CC)CC(=O)Nc1c(C)cccc1C</smiles>

(I)<smiles>CC(C)NCC(O)COc1cccc2ccccc12</smiles>

(II)<smiles></smiles>

(III)<smiles>C[N+]1(C)CCC(OC(=O)C(CO)c2ccccc2)C2CC1C1OC21</smiles>

(IV)<smiles>C=CC=CC=CCC1CC(OC(=O)C(CO)c2ccccc2)CC2COC1C2</smiles>

(V)<smiles>CCC[n+]1ccc2ccccc2c1</smiles>

(VI)

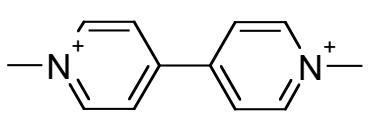

(VII)

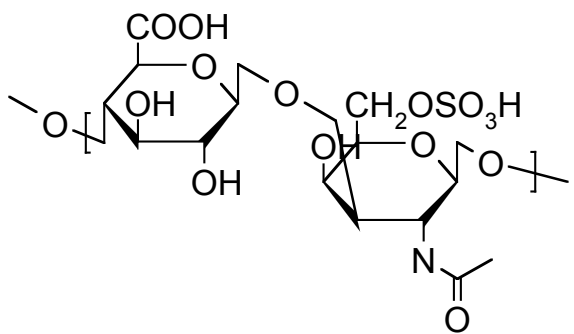

(VIII)

Fig. (1). Structures of the low-molecular-weight ligands lidocaine (I), propranolol (II), scopolamine (III), N-methyl scopolamine (IV), Nbutyl scopolamine (V), 2-propylisochinolinium (VI), and methyl viologen (VII) and the glycosaminoglycan chondroitin-6-sulfate (VIII).

bromide, N-methyl scopolamine bromide, and $( \pm)$ propranolol hydrochloride were obtained from Sigma (St. Louis, MO, USA). Methyl viologen dichloride (paraquat dichloride, 1, 1'-dimethyl-4, 4' -bipyridinium dichloride) and 2-propylisochinolinium bromide were obtained from Aldrich (Steinheim, Germany). Scopolamine hydrobromide trihydrate was purchased from Merck (Darmstadt, Germany). Purified water from a Milli-Q deionization unit (Millipore, Bedford, MA, USA) was used throughout.

\section{Apparatus}

Capillary electrophoresis was conducted using a Beckman PACE MDQ equipped with a diode array detector (Beckman, Fullerton, CA). UV detection was performed at 205, 206, or $209 \mathrm{~nm}$ depending on the UV absorbance maximum of the ligand. Electropherograms were recorded using the Beckman 24-Karat software. The uncoated fused silica (Polymicro Technologies, Phoenix, AZ, USA) and polyvinyl alcohol (PVA) coated capillaries (Agilent Technologies, Waldbronn, Germany) were $31.2 \mathrm{~cm} \times 50 \mu \mathrm{m}$ ID and with a length of $20 \mathrm{~cm}$ to the detector.

The $\mathrm{pH}$ measurements were performed using a Metrohm 744 pH Meter (Metrohm Ltd., Herisau, Switzerland).

\section{Buffer and Sample Preparation}

The buffer used for electrophoresis and samples was a 67 $\mathrm{mM}$ sodium phosphate buffer, $\mathrm{pH}$ 7.40. Samples contained $50.0 \mathrm{~g} / \mathrm{L}$ chondroitin sulfate corresponding to a molar concentration of disaccharide units of $1.04 \times 10^{-1} \mathrm{M}$ when the repeat unit of bovine cartilage chondroitin sulfate is assumed to have the molecular formula $\mathrm{C}_{14} \mathrm{H}_{20} \mathrm{NNaO}_{14} \mathrm{~S}$. The sample concentrations of the low-molecular-weight ligands ranged from 10 to $500 \mu \mathrm{M}$. Standards covering the concentration range 2 or 5 to $500 \mu \mathrm{M}$ were used to prepare calibration curves.

\section{CE-FA Experiments}

Uncoated fused silica capillaries were conditioned for 30 min each with $1 \mathrm{M}$ sodium hydroxide, water, and electrophoresis buffer. The PVA coated capillary was conditioned for $10 \mathrm{~min}$ each with $10 \mathrm{mM}$ phosphoric acid and the CE buffer. Between the measurements the uncoated capillaries were flushed for $1 \mathrm{~min}$ each with $0.1 \mathrm{M}$ sodium hydroxide and phosphate buffer whereas the PVA coated capillary was rinsed with $10 \mathrm{mM}$ phosphoric acid and phosphate buffer ( $\mathrm{pH}$ 7.4) (1 min each). The sample tray and the capillary cartridge temperature were set to $25^{\circ} \mathrm{C}$ and 
$23^{\circ} \mathrm{C}$, respectively. The applied voltage was $8 \mathrm{kV}(\sim 47 \mu \mathrm{A})$. Samples were introduced into the short end of the capillary by pressure $(0.5 \mathrm{psi})$ with duration of $15 \mathrm{~s}$ and $8 \mathrm{~s}$ for standards and samples, respectively, except for methyl viologen where $30 \mathrm{~s}$ and $15 \mathrm{~s}$ injection times, respectively, were applied. The concentration of free ligand in the samples was determined from the height of the plateau peaks using calibration curves.

\section{Data Analysis}

The construction of binding isotherms for determination of the apparent association constant $K_{\text {app }}$ has been described previously [19]. Briefly, the binding density, $v$, was calculated from the measured free ligand concentration $[\mathrm{L}]_{\text {free }}$, the total ligand concentration $[\mathrm{L}]_{\text {total }}$, and the molar concentration of chondroitin sulfate disaccharide units, $C_{\mathrm{CS}}$ :

$v=\frac{[L]_{\text {bound }}}{C_{C S}}=\frac{\left([L]_{\text {total }}-[L]_{\text {free }}\right)}{C_{C S}}$

The apparent association constant, $\mathrm{K}_{\mathrm{app}}$, was determined from the slopes of the binding isotherms ( $\left.v v s[\mathrm{~L}]_{\text {free }}\right)$.

\section{RESULTS AND DISCUSSION}

\section{Method Development}

Initial experiments were conducted using propranolol as the ligand. Fig. (2) shows the effect of increasing injection times for propranolol standards and samples (propranolol and chondroitin sulfate) introduced by pressure $(0.5 \mathrm{psi})$ from the short end of the capillary. Due to the different charge states the analyte is easily separated from the chondroitin sulfate. Frontal analysis conditions [53], where plateau peaks are observed, were achieved using injection times above $8 \mathrm{~s}$ and $5 \mathrm{~s}$ for standards and samples, respectively. In addition to propranolol, a UV signal for chondroitin sulfate and EOF was observed in the sample electropherograms (Fig. 2B). In CE-FA equilibrium is maintained during the separation due to the large sample volumes. The measured peak heights are proportional to the (free) ligand concentrations in the samples. Complexation between propranolol and the glycosaminoglycan is apparent as a decrease in plateau peak height and broadening of the propranolol peak in samples relative to the standards without chondroitin sulfate present (Fig. 2).

Qualitatively similar electropherograms were obtained for lidocaine, scopolamine, N-methyl scopolamine, N-butyl scopolamine, and 2-propylisochinolinium. In line with previous studies [19], strong adsorption to the fused silica capillary wall was observed for methyl viologen (paraquat). Methyl viologen adsorbed onto PVA coated capillaries to a lesser extent indicating that the PVA coated capillary should be applied in the affinity studies encompassing methyl viologen. Upon selection of the operating conditions calibration curves were constructed. The between run repeatability of plateau peak heights was assessed and the R.S.D.s were below $3 \%$ for both standards and samples $(n=3)$ in most cases. A primary objective of the investigations was to develop a rapid method for assessing the complexation of low-molecular-weight ligands to chondroitin sulfate. Total analysis times (single standard/sample), including rinsing, and sample introduction were less than $5 \mathrm{~min}$. Consequently, estimates of the degree of ligand complexation (requiring the analysis of one sample and one standard solution) can be obtained in $10 \mathrm{~min}$.
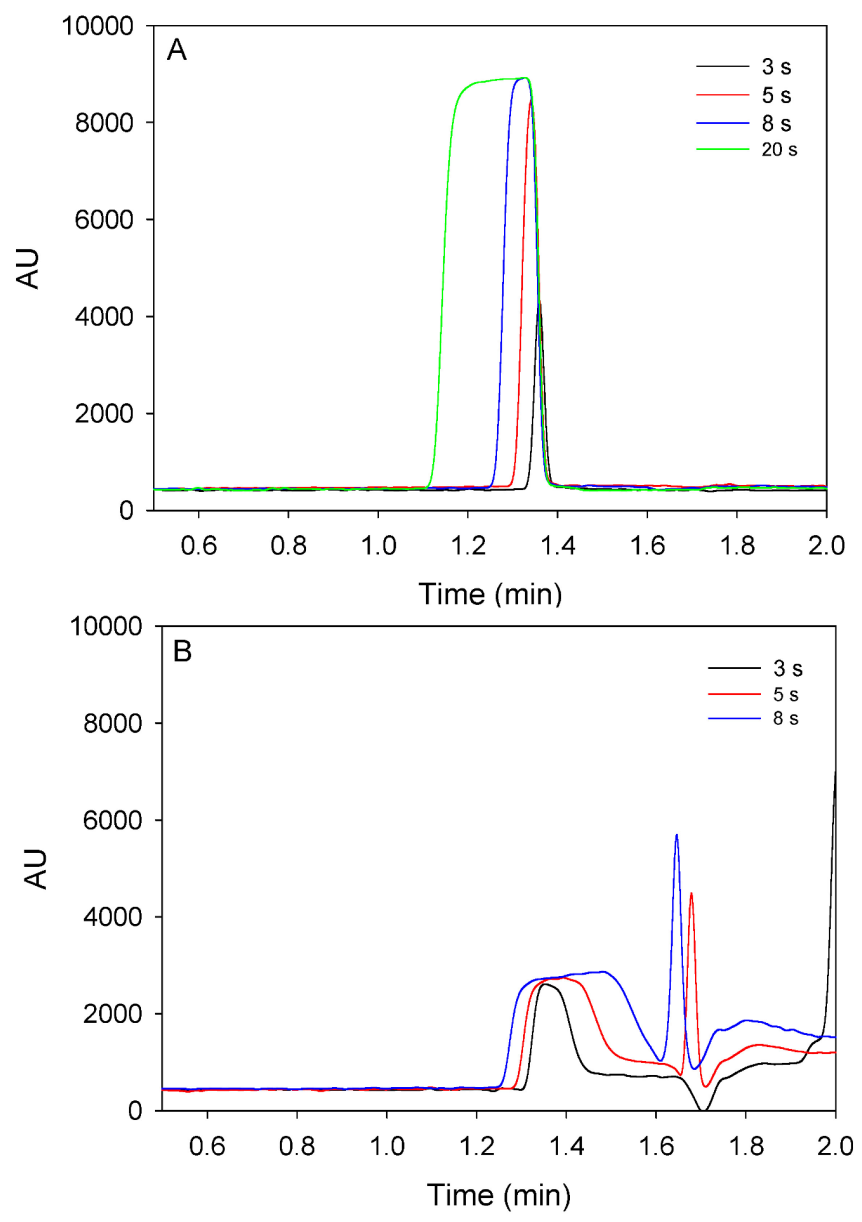

Fig. (2). Complexation of propranolol with chondroitin sulfate as studied by CE-FA. Electropherograms of $100 \mu \mathrm{M}$ propranolol standards and samples containing $50 \mathrm{~g} / \mathrm{L}$ chondroitin sulfate in 67 $\mathrm{mM}$ phosphate buffer ( $\mathrm{pH}$ 7.40). (A) standards. (B) samples. Conditions: Uncoated fused silica capillary $(31.2 \mathrm{~cm} \times 50 \mu \mathrm{m}$ ID, $11 \mathrm{~cm}$ effective length); applied voltage $8 \mathrm{kV}(\sim 47 \mu \mathrm{A})$; detection at $209 \mathrm{~nm}$; hydrodynamic injection for $3-20 \mathrm{~s}(0.5 \mathrm{psi})$ from the short end; sample tray temperature $25^{\circ} \mathrm{C}$; capillary cassette temperature $23^{\circ} \mathrm{C}$.

\section{Ligand-Chondroitin Sulfate Complexation}

The binding isotherms obtained for low-molecularweight ligand-chondroitin sulfate complexation using CEFA are depicted in Fig. (3). The isotherms depicting binding density $v$ as a function of the free ligand concentration were linear. In all cases $v$ was less than 0.01 . It is known that for $v$ $\rightarrow 0$, the binding equations reduce to $v /[L]_{\text {free }}=K_{\text {app }}[19,54]$. Thus, the apparent association constant $\mathrm{K}_{\mathrm{app}}$ was determined form the slopes of the binding isotherms. The determined $\mathrm{K}_{\mathrm{app}}$-values are summarized in Table 1. Alternatively, the association constants may be determined by extrapolation $\left(v /[\mathrm{L}]_{\text {free }} v s[\mathrm{~L}]_{\text {free }}\right)$ as described by Klotz [54]. This approach was found to provide equivalent results (Table 1).

The investigated ligands may be ranked with respect to their affinity for chondroitin sulfate according to the 


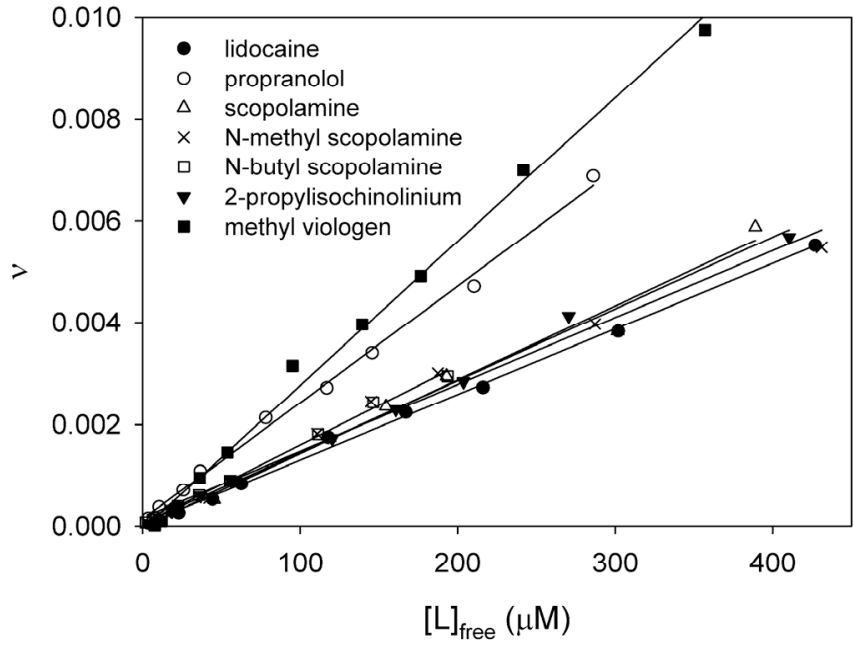

Fig. (3). Binding isotherms obtained by CE-FA. Interaction of lowmolecular-weight ligands with chondroitin sulfate $(50 \mathrm{~g} / \mathrm{L})$ in 67 $\mathrm{mM}$ phosphate buffer $(\mathrm{pH} 7.40)$ at $25^{\circ} \mathrm{C}$.

Table 1. Degree of Complexation of Low-Molecular-Weight Ligands to Chondroitin Sulfate $\left(50 \mathrm{~g} \mathrm{~L}^{-1} ; 1.04 \times 10^{-1}\right.$ $M)$ and Apparent Association Constants, $K_{\text {app}}$, Determined by Capillary Electrophoresis Frontal Analysis in 0.067 M Phosphate Buffer (pH 7.4) at $25^{\circ} \mathrm{C}$

\begin{tabular}{|l|c|}
\hline \multicolumn{1}{|c|}{ Compound } & $\mathbf{K}_{\text {app }}\left(\mathbf{M}^{-1}\right)$ \\
\hline \hline Lidocaine & $13^{\mathrm{a}} / 13^{\mathrm{b}}$ \\
\hline Propranolol & $23^{\mathrm{a}} / 28^{\mathrm{b}}$ \\
\hline Scopolamine & $14^{\mathrm{a}} / 14^{\mathrm{b}}$ \\
\hline N-methyl scopolamine & $13^{\mathrm{a}} / 15^{\mathrm{b}}$ \\
\hline N-butyl scopolamine & $16^{\mathrm{a}} / 17^{\mathrm{b}}$ \\
\hline 2-Propylisochinolinium & $14^{\mathrm{a}} / 15^{\mathrm{b}}$ \\
\hline Methyl viologen & $28^{\mathrm{a}} / 29^{\mathrm{b}}$ \\
\hline
\end{tabular}

${ }^{\mathrm{a}} \mathrm{K}_{\mathrm{app}}$ Determined from the slope of the binding isotherm.

${ }^{b} K_{\text {app }}$ Determined by extrapolation from plots of $v /[L]_{\text {free }}$ as a function of $[\mathrm{L}]_{\text {free }}$.

obtained $\mathrm{K}_{\mathrm{app}}$-values: lidocaine $\approx \mathrm{N}$-methyl scopolamine $\approx$ scopolamine $\approx 2$-propylisochinolinium $<$ propranolol $<$ methyl viologen. At the selected experimental conditions ( $\mathrm{pH} 7.4$ and $25^{\circ} \mathrm{C}$ ), the low-molecular-weight ligands are positively charged and chondroitin sulfate is negatively charged (Fig. 1). The presence of chondroitin sulfate in the phosphate buffer was found to lower the $\mathrm{pH}$ to 7.26. Lidocaine, propranolol, and scopolamine have $\mathrm{pK}_{\mathrm{a}}$ values of $7.86,9.45$, and 7.55 [55], respectively, and the degree of ionization at $\mathrm{pH} 7.4(7.26)$ is 0.74 (0.80), 0.99 (0.99), and $0.59(0.66)$, respectively. N-methyl scopolamine and N-butyl scopolamine are permanently charged due to the presence of a quaternary amino group. 2-propylisochinolinium and methyl viologen (paraquat) possess one and two permanently charged quaternary nitrogen functional groups, respectively. Except for propranolol, the ligands carrying only one charge/ionizable group displayed almost similar affinity for chondroitin sulfate. Electrostatic interactions are expected to play an important role in the complexation reaction $[16,50]$. However, the lower degrees of ionization for lidocaine and scopolamine did not manifest in lower degrees of complexation (as compared to the other monovalent ligands). The fact that scopolamine and its quaternized derivatives exhibit similar affinity towards chondroitin sulfate indicates that sterical effect and/or hydrophobic effects are of minor importance or cancel out with the decreased fraction of ionized scopolamine. The cause for the relatively high degree of propranolol complexation is not clear but may be related to differences in lipophilicity or the presence of the $\beta$-hydroxy group which may participate in hydrogen bonding. As expected, and in agreement with previous studies on chondroitin sulfate binding comparing mono- and dicationic species [50], methyl viologen exhibited the highest affinity for chondroitin sulfate. Santos et al. [16] also investigated the binding of propranolol to chondroitin sulfate using isothermal titration calorimetry, however, under different experimental conditions (ionic strength) making direct comparison difficult.

Ishwar et al. used mobility shift affinity CE to investigate the affinity of two dodecapeptides for chondroitin sulfate and heparin [53]. To the best of our knowledge this study represents the first application of CE-FA for investigation of chondroitin sulfate complexation. An advantage, at least in some applications, of CE-FA as compared mobility shift affinity $\mathrm{CE}$ may be that free ligand concentrations are provided directly as the output. CE-FA was found suitable for ranking and quantification of low-molecular-weight ligand complexation with chondroitin sulfate. With the experimental conditions applied in the current CE-FA study only the lower part of the chondroitin sulfate binding isotherm were characterized and, consequently, the results are not suitable for obtaining information on the number of ligand binding sites per glycosaminoglycan disaccharide unit in contrast to other methods reported $[16,50]$. This might be accomplished for some ligands also by CE-FA through appropriate modification of the experimental conditions, i.e. adjustment of chondroitin sulfate concentration, ligand concentration and/or ionic strength. However, this was considered beyond the scope of the present study.

\section{CONCLUSIONS}

In the present study a CE-FA method feasible for studying low-molecular-weight ligand binding to the glycosaminoglycan chondroitin sulfate was developed. CEFA is an attractive method for studying ligand-chondroitin sulfate interactions due to the low sample consumption and the short analysis times obtained. Ranking of low-molecularweight ligand complexation with chondroitin sulfate was achieved based on CE-FA results. Except from propranolol the monovalent cationic ligands possessed almost similar affinity for chondroitin sulfate. The complexation of propranolol was intermediate between the single charged ligands and methyl viologen carrying two positive charges and exhibiting the strongest interaction with chondroitin sulfate. CE-FA may constitute a feasible tool for characterization of ligand-glycosaminoglycan complexation in drug research.

\section{ACKNOWLEDGEMENTS}

This work was supported by The Danish Medical Research Council. The authors thank Elise Mortensen for 
technical support with the capillary eletrophoresis experiments.

\section{ABBREVIATIONS}

$\begin{array}{lll}\mathrm{ACE} & =\text { Affinity capillary electrophoresis } \\ \mathrm{CE} & =\text { Capillary electrophoresis } \\ \mathrm{CE}-\mathrm{FA} & =\text { Capillary electrophoresis frontal analysis } \\ \mathrm{PVA}= & \text { Polyvinyl alcohol } \\ \text { REFERENCES }\end{array}$

[1] Koeberle, M.J.; Hughes, P.M.; Skellern, G.G.; Wilson, C.G. Binding of memantine to melanin: influence of type of melanin and characteristics. Pharm. Res., 2003, 20, 1702-1709.

[2] Kikuchi, S.; Inaba, A.; Takahashi, M.; Aramaki, Y.; Tsuchiya, S. Decreased distribution of gentamicin in rat kidney by complexation with dextran sulfate. Int. J. Pharm., 1988, 42, 193-198.

[3] Larsson, B.; Nilsson, M.; Tjälve, H. The binding of inorganic and organic cations and $\mathrm{H}^{+}$to cartilage in vitro. Biochem. Pharmacol., 1981, 30, 2963-2970.

[4] Dollo, G.; Malinovsky, J.-M.; Péron, A.; Chevanne, F.; Pinaud, M.; Le Verge, R.; Le Corre, P. Prolongation of epidural bupivacaine effects with hyaluronic acid in rabbits. Int. J. Pharm., 2004, 272, 109-119.

[5] Larsen, N.E.; Balazs, E.A. Drug delivery systems using hyaluronan and its derivatives. Adv. Drug Del. Rev., 1991, 7, 279-293.

[6] Tsai, M.; Chiang, Y.; Wang, L.; Huang, G.; Wu, P. Oral sustained delivery of diclofenac sodium using calcium chondroitin sulfate matrix. J. Biomater. Sci. Polymer Edn., 2005, 16, 1319-1331.

[7] Zhao, Q.; Li, B. pH-controlled drug loading and release from biodegradable microcapsules. Nanomedicine, 2008, 4, 302-310.

[8] Benoit, E.; Prot, O.; Maincent, P.; Bessière, J. Adsorption of betablockers onto polyisobutylcyanoacrylate nanoparticles measured by depletion and dielectric methods. Pharm. Res., 1994, 11, 585-588.

[9] Fu Lu, M.-Y.; Borodkin, S.; Woodward, L.; Li, P.; Diesner, C.; Hernandez, L.; Vadnere, M. A polymer carrier system for taste masking of macrolide antibiotics. Pharm. Res., 1991, 8, 706-712.

[10] Jenquin, M.R.; McGinity, J.W. Characterization of acrylic resin matrix films and mechanisms of drug-polymer interactions. Int. J. Pharm., 1994, 101, 23-34.

[11] Caram-Lelham, N.; Sundelöf, L.-O. Some aspects on characterization and properties of charged polysaccharides. An investigation of the system carrageenan/amitriptyline/water with relation to amphiphile adsorption and charge density. Int. $J$. Pharm., 1995, 115, 103-111.

[12] Caram-Lelham, N.; Sundelöf, L.-O. The effect of hydrophobic character of drugs and helix-coil transition of K-carrageenan on the polyelectrolyte-drug interaction. Pharm. Res., 1996, 13, 920-925.

[13] Nagwekar, J.B.; Kostenbauder, H.B. Utilization of a model copolymer to evaluate the contribution of hydrophobic bonding in drug binding. J. Pharm. Sci., 1970, 59, 751-757.

[14] Ehtezazi, T.; Govender, T.; Stolnik, S. Hydrogen bonding and electrostatic interaction contributions to the interaction of a cationic drug with polyaspartic acid. Pharm. Res., 2000, 17, 871-878.

[15] Govender, T.; Ehtezazi, T.; Stolnik, S.; Illum, L.; Davis, S.S. Complex formation between the anionic polymer (PAA) and a cationic drug (procaine $\mathrm{HCl}$ ): Characterization by microcalorimetric studies. Pharm. Res., 1999, 16, 1125-1131.

[16] Santos, H.A.; Manzanares, J.A.; Murtomäki, L.; Kontturi, K. Thermodynamic analysis of binding between drugs and glycosaminoglycans by isothermal titration calorimetry and fluorescence spectroscopy. Eur. J. Pharm. Sci., 2007, 32, 105-114.

[17] Hayakawa, K.; Kwak, J.C.T. Surfactant-polyelectrolyte interactions. 1. Binding of dodecyltrimethylammonium ions by sodium dextran sulfate and sodium poly(styrenesulfonate) in aqueous solution in the presence of sodium chloride. J. Phys. Chem., 1982, 86, 3866-3870.

[18] Malovikova, A.; Hayakawa, K.; Kwak, J.C.T. Surfactantpolyelectrolyte interactions. 4 . Surfactant chain lenght dependence of the binding of alkylpyridinium cations to dextran sulfate. $J$. Phys. Chem., 1984, 88, 1930-1933.

[19] Østergaard, J.; Khanbolouki, A.; Jensen, H.; Larsen, C. Complexation between low molecular weight cationic ligands and negatively charged polymer as studied by capillary electrophoresis frontal analysis. Electrophoresis, 2004, 25, 3168-3175.

[20] Jensen, H.; Østergaard, J.; Thomsen, A.E.; Hansen, S.H. CE frontal analysis based on simultaneous UV and contactless conductivity detection: A general setup for studying noncovalent interactions. Electrophoresis, 2007, 28, 322-327.

[21] Heegaard, N.H.H. A heparin-binding peptide from human serum amyloid $\mathrm{P}$ component characterized by affinity capillary electrophoresis. Electrophoresis, 1998, 19, 442-447.

[22] McKeon, J.; Holland, L.A. Determination of dissociation constants for a heparin-binding domain of amyloid precursor protein and heparins or heparan sulfate by affinity capillary electrophoresis. Electrophoresis, 2004, 25, 1243-1248.

[23] Heegaard, N.H.H.; Kennedy, R.T. Identification, quantitation, and characterization of biomolecules by capillary electrophoretic analysis of binding interactions. Electrophoresis, 1999, 20, 31223133.

[24] He, X.; Ding, Y.; Li, D.; Lin, B. Recent advances in the study of biomolecular interactions by capillary electrophoresis. Electrophoresis, 2004, 25, 697-711.

[25] Heegaard, N.H.H. Applications of affinity interactions in capillary electrophoresis. Electrophoresis, 2003, 24, 3879-3891.

[26] Rundlett, K.L.; Armstrong, D.W. Methods for the determination of binding constants by capillary electrophoresis. Electrophoresis, 2001, 22, 1419-1427.

[27] Chen, Z.; Weber, S.G. Determination of binding constants by affinity capillary electrophoresis, electrospray ionization mass spectrometry and phase-distribution methods. Trends Anal. Chem., 2008, 27, 738-748.

[28] Liu, X.; Dahdouh, F.; Salgado, M.; Gomez, F.A. Recent advances in affinity capillary electrophoresis (2007). J. Pharm. Sci., 2009, 98, 394-410.

[29] Busch, M.H.A.; Carels, L.B.; Boelens, H.F.M.; Kraak, J.C.; Poppe, H. Comparison of five methods for the study of drug-protein binding in affinity capillary electrophoresis. J. Chromatogr. A, 1997, 777, 311-328.

[30] Guijt-van Duijn, R.M.; Frank, J.; van Dedem, G.W.K.; Baltussen, E. Recent advances in affinity capillary electrophoresis. Electrophoresis, 2000, 21, 3905-3918.

[31] Tanaka, Y.; Terabe, S. Estimation of binding constants by capillary electrophoresis. J. Chromatogr. B, 2002, 768, 81-92.

[32] Østergaard, J.; Heegaard, N.H.H. Capillary electrophoresis frontal analysis: Principles and applications for the study of drug-plasma protein binding. Electrophoresis, 2003, 24, 2903-2913.

[33] Østergaard, J.; Heegaard, N.H.H. Bioanalytical interaction studies executed by preincubation affinity capillary electrophoresis. Electrophoresis, 2006, 27, 2590-2608.

[34] Ishihama, Y.; Miwa, T.; Asakawa, N. Drug-plasma protein binding assay by electrokinetic chromatography-frontal analysis. Electrophoresis, 2002, 23, 951-955.

[35] Jia, Z.; Ramstad, T.; Zhong, M. Determination of protein-drug binding constants by pressure-assisted capillary electrophoresis (PACE)/frontal analysis (FA). J. Pharm. Biomed. Anal., 2002, 30, 405-413.

[36] McDonnell, P.A.; Caldwell, G.W.; Masucci, J.A. Using capillary electrophoresis/frontal analysis to screen drugs interacting with human serum proteins. Electrophoresis, 1998, 19, 448-454.

[37] Ohara, T.; Shibukawa, A.; Nakagawa, T. Capillary electrophoresis/frontal analysis for microanalysis of enantioselective protein binding of a basic drug. Anal. Chem., 1995, 67, 3520-3525.

[38] Gotti, R.; Bertucci, C.; Andrisano, V.; Pomponi, R.; Cavrini, V. Study of donezepil binding to serum albumin by capillary electrophoresis and circular dichroism. Anal. Bioanal. Chem., 2003, 377, 875-879.

[39] Østergaard, J.; Schou, C.; Larsen, C.; Heegaard, N.H.H. Evaluation of capillary electrophoresis frontal analysis for the study of low molecular weight drug-human serum albumin interactions. Electrophoresis, 2002, 23, 2842-2853.

[40] Østergaard, J.; Schou, C.; Larsen, C.; Heegaard, N.H.H. Effect of dextran as a run buffer additive in drug-protein binding studies using capillary electrophoresis frontal analysis. Anal. Chem., 2003, $75,207-214$

[41] Zhao, P.; Zhu, G.; Zhang, W.; Zhang, L.; Liang, Z.; Zhang, Y. Study of multiple binding constants of dexamethansone with human serum albumin by capillary electrophoresis-frontal analysis 
and multivariate regression. Anal. Bioanal. Chem., 2009, 393, 257261.

[42] Sun, H.; He, P. Characterization of interaction between doxycycline and human serum albumin by capillary electrophoresis-frontal analysis. Electrophoresis, 2009, 30, 19911997.

[43] Diniz, A.; Escuder-Gilabert, L.; Lopes, N.P.; Villanueva-Camañas, R.M.; Sagrado, S.; Medina-Hernández, M.J. Characterization of interactions between polyphenolic compounds and human serum proteins by capillary electrophoresis. Anal. Bioanal. Chem., 2008, 391, 625-632.

[44] Kuroda, Y.; Cao, B.; Shibukawa, A.; Nakagawa, T. Effect of oxidation of low-density lipoprotein on drug binding affinity studied by high performance frontal analysis-capillary electrophoresis. Electrophoresis, 2001, 22, 3401-3407.

[45] Mohamed, N.A.L.; Kuroda, Y.; Shibukawa, A.; Nakagawa, T.; Gizawy, S.E.; Askal, H.F.; Kommos, M.E.E. Binding analysis of nilvadipine to plasma lipoproteins by capillary electrophoresisfrontal analysis. J. Pharm. Biomed. Anal., 1999, 21, 1037-1043.

[46] Mohamed, N.A.L.; Kuroda, Y.; Shibukawa, A.; Nakagawa, T.; Gizawy, S.E.; Askal, H.F.; Kommos, M.E.E. Enantioselective binding analysis of verapamil to plasma lipoproteins by capillary electrophoresis-frontal ananlysis. J. Chromatogr. A, 2000, 875, 447-453.

[47] Franzen, U.; Jorgensen, L.; Larsen, C.; Heegaard, N.H.H.; Østergaard, J. Determination of liposome-buffer distribution coefficients of charged drugs by capillary electrophoresis frontal analysis. Electrophoresis, 2009, 30, 27711-27719.

[48] Østergaard, J.; Jorgensen, L.; Thomsen, A.E.; Larsen, S.W.; Larsen, C.; Jensen, H. Drug - liposome distribution phenomena studied by capillary electrophoresis frontal analysis. Electrophoresis, 2008, 29, 3320-3324.

[49] Carney, S.L.; Muir, H. The structure and function of cartilage proteoglycans. Physiol. Rev., 1988, 68, 858-910.

[50] Olsen, G.D.; Chan, E.M.; Riker, W.K. Binding of d-tubocurarine di[methyl- $\left.{ }^{14} \mathrm{C}\right]$ ether iodide and other amines to cartilage, chondroitin sulfate and human plasma proteins. J. Pharmacol. Exp. Ther., 1975, 195, 242-250.

[51] Ishwar, A.R.; Jeong, K.J.; Panitch, A.; Akkus, O. Raman spectroscopic investigation of peptide-glycosaminoglycan interactions. Appl. Spectrosc., 2009, 63, 636-641.

[52] Larsen, C.; Østergaard, J.; Larsen, S.; Jensen, H.; Jacobsen, S. Lindegaard, C.; Andersen, P.H. Intra-articular depot formulation principles: Role in the management of postoperative pain and arthritic disorders. J. Pharm. Sci., 2008, 97, 4622-4654.

[53] Østergaard, J.; Hansen, S.H.; Jensen, H.; Thomsen, A.E. Preequilibrium capillary zone electrophoresis or frontal analysis: Advantages of plateau peak conditions in affinity capillary electrophoresis. Electrophoresis, 2005, 26, 4050-4054.

[54] Klotz, I. M. Ligand-receptor energetics. A guide for the perplexed; John Wiley \& Sons: New York, 1997.

[55] Newton, D.W.; Kluza, R.B. $\mathrm{pK}_{\mathrm{a}}$ values of medicinal compounds in pharmacy practice. Drug Intell. Clin. Pharm., 1978, 12, 546-554.

Received: July 29, 2009

(C) Østergaard et al.; Licensee Bentham Open.

This is an open access article licensed under the terms of the Creative Commons Attribution Non-Commercial License (http://creativecommons.org/licenses/by-nc/

$3.0 /$ ) which permits unrestricted, non-commercial use, distribution and reproduction in any medium, provided the work is properly cited. 